\title{
Distribution, diffusive fluxes, and toxicity of heavy metals and PAHs in pore water profiles from the northern bays of Taihu Lake
}

\author{
Pei Lei ${ }^{1,2} \cdot$ Hong Zhang $^{1} \cdot$ Baoqing Shan ${ }^{1} \cdot{\text { Bozheng } \text { Zhang }^{3}}^{3}$
}

Received: 28 March 2016 / Accepted: 11 August 2016 / Published online: 19 August 2016

(C) Springer-Verlag Berlin Heidelberg 2016

\begin{abstract}
Pore water plays a more significant role than do sediments in pollutant cycling dynamics. Also, concentrations of pollutants in pore water provide important information about their bioavailability or eco-toxicity; however, very few studies have focused on this topic. In this study, four duplicate sediment cores from three typical northern bays as well as the central part of Taihu Lake were collected to investigate the distribution, diffusive fluxes, and toxicity of heavy metals and polycyclic aromatic hydrocarbons (PAHs) in pore water profiles, which will be good in understanding the mobility and toxicity of these toxic pollutants and achieving better environmental management. The diffusive fluxes of heavy metals across the sediment-water interface was estimated through Fick's First Law, and the toxicity of heavy metals and PAHs in pore water was assessed by applying a water quality index (interstitial water toxicity criteria unit, IWCTU) and a hazard index (HI), respectively. The average concentrations of $\mathrm{Cr}$,
\end{abstract}

Responsible editor: Ester Heath

Electronic supplementary material The online version of this article (doi:10.1007/s11356-016-7467-6) contains supplementary material, which is available to authorized users.

Hong Zhang

hongzhang@rcees.ac.cn

Baoqing Shan

bqshan@rcees.ac.cn

1 State Key Laboratory of Environmental Aquatic Chemistry, Research Center for Eco-Environmental Sciences, Chinese Academy of Sciences, 18th Shuangqing Road, Haidian District, Beijing 100085, China

2 University of Chinese Academy of Sciences, Beijing 100049, China

3 Lanzhou LS Group Co., Ltd., Lanzhou 730050, China
$\mathrm{Cu}, \mathrm{Ni}, \mathrm{Pb}$, and $\mathrm{Zn}$ in surface pore water were 18.8, 23.4, 12.0, 13.5, and $42.5 \mu \mathrm{g} \mathrm{L}^{-1}$, respectively. Also, concentrations of the selected heavy metals in both overlying water and pore water from Taihu Lake were all lower than the standard values of the environmental quality standards for surface water. The concentrations as the pore water depth increased, and the highest detected concentrations of heavy metals were recorded between 3 and $5 \mathrm{~cm}$ below the sediment surface. The average diffusive fluxes of these metals were 27.3, 24.8, 7.03, 7.81 , and $-3.32 \mu \mathrm{g}\left(\mathrm{m}^{2} \text { day }\right)^{-1}$, respectively, indicating export from sediment into overlying water, with the exception of $\mathrm{Zn}$. There was a potential risk of toxicity, mainly from $\mathrm{Pb}$ and $\mathrm{Cu}$, indicating that heavy metals in pore water had slight to moderate impact on sediment-dwelling organisms by values of the IWCTU and the Nemeraw index. The total PAH concentrations in pore water were higher than those in overlying water, and such gradient implies a potential flux of PAHs from pore water to overlying water. The average HI value of PAHs in surface pore water showed no or low ecological risk. While there may be occasional risk due to the HI values in some sites being greater than 1, the dominant contributors were carcinogenic PAHs. Because of their potential biological impact, heavy metals and PAHs and their comprehensive toxic effects in pore water should be given priority attention to keep the safety of Taihu Lake.

Keywords Diffusive flux $\cdot$ Heavy metals $\cdot$ PAHs $\cdot$ Pore water - Taihu Lake · Toxicity

\section{Introduction}

The discharge of industrial effluent induced by intensive urbanization and economic development in recent years has led to a substantial increase in the concentrations of pollutants 
(e.g., nutrients, heavy metals, and organic contaminants) in riverine, lacustrine, and marine sediment (Von der Heyden and New 2004; Gao et al. 2015). Therefore, aquatic sediments are often recognized as a major sink for these pollutants. Pore water, the water that fills the interspace between the sedimentary grains, has been shown to supply dissolved contaminants to the water column through the sediment-water interface (Santos-Echeandia et al. 2009; Polizzotto et al. 2008). Therefore, pore water plays important geochemical and ecological roles in the cycling dynamics of pollutants, which were regarded as the "medium" for pollutants exchange both in sedimentary particles and overlying water (Escher and Hermens 2004). In addition, the fraction of pollutants in pore water is considered to be more biologically available than the sedimentary fraction in the aquatic environment (Harmsen 2007). Once there are exchanges across the sediment-water interface, pollutants in pore water can be released to the water column via chemical or biological processes and then pose a potential risk to sediment-dwelling organisms and ecosystems. This interaction is particularly prominent for shallow lakes, which frequently undergo strong changes in both hydraulic and physical-chemical conditions due to wind-wave action (Zhu et al. 2005).

Taihu Lake, a typical shallow lake with an average depth of $1.9 \mathrm{~m}$, is located in the Yangtze River Delta and is the third largest freshwater lake in China (Zhang et al. 2012). This lake serves a variety of functions, such as supplying drinking water, flood control, shipping, fisheries, and tourism (Qin et al. 2007). However, with rapid industrialization and urbanization, anthropogenic pollutants derived from household, industrial, and agricultural activities in the surrounding metropolis have been discharged into the lake, especially for the northern bays, leading to a serious deterioration of water quality of the lake. In addition, increasing energy consumption, combined with a lack of effective management and technical measures in this region during the last several decades, has caused dramatic increases in the concentrations of some toxic pollutants, such as heavy metals and polycyclic aromatic hydrocarbons (PAHs), in the sediments of Taihu Lake (Liu et al. 2009; Tao et al. 2012).

Several publications have reported on the occurrence of heavy metals or PAHs in sediments or water matrices from Taihu Lake. For instance, a comprehensive exploration on heavy metal status in surface sediments from Taihu Lake had been conducted by Tao et al. (2012), and the results indicated that the sediments in the Lake were widely contaminated with heavy metals and probably pose potential ecological risks. Zhang et al. (2011) found that the total PAH concentrations in overlying water and pore water were more than $10,000 \mathrm{ng} \mathrm{L}^{-1}$ and the northern bays of Taihu Lake were the most heavily polluted areas. However, most of these researches just focused on the spatial characteristics of pollution in surface sediments, and little information about the diffusive flux or toxicological risk of these toxic pollutants in pore water profiles could be acquired. In addition, supplying drinking water for large cities (such as Shanghai City and Wuxi City) is one of the most important functions of Taihu Lake (Tao et al. 2010). Therefore, exploring the distribution and risk of toxic pollutants in pore water profiles from the heavily polluted areas of Taihu Lake is necessary to protect these water resources and human health.

Here, three typical northern bays as well as the central part of Taihu Lake were selected to (a) investigate the distributions of 5 heavy metals and 16 priority PAHs in pore water profiles, (b) estimate the diffusive fluxes of heavy metals across the sediment-water interface, and (c) assess the toxicity of heavy metals and PAHs in pore water. The results will be helpful in better understanding the mobility and toxicity of heavy metals and PAHs in the lacustrine ecosystem, which aim to achieve a more highly targeted environmental management for this important region.

\section{Materials and methods}

\section{Sediment sampling}

The northern bays of Taihu Lake are heavily impacted urban bays, with inputs of contaminants from numerous anthropogenic sources. Three bays including Zhushan Bay (ZS), Meiliang Bay (ML), and Gonghu Bay (GH) were selected as study areas, and the central part of the Lake (CL) was sampled for comparison purposes (Fig. 1). At each site, two duplicate sediment cores were collected in November 2014 to determine heavy metals and PAHs in pore water and the corresponding overlying water, respectively. Samples were taken by a sediment core sampler (Corer 60; Uwitec, Austria) with a length of $60 \mathrm{~cm}$ and an inner diameter of $6 \mathrm{~cm}$. Special core catch (ball) works automatically without faulty messenger, and the sediment cores could be taken from the bottom of aquatic systems with minimal disturbance to the sediment-water interface. Sediments, as well as the overlying water and pore water as a whole, will be simultaneously collected and the original status maintained as much as possible.

\section{Sample extraction}

When analyzing heavy metals, overlying water was sucked out at a $5-\mathrm{cm}$ interval using a siphon pre-immersed in nitric acid within $48 \mathrm{~h}$ of sampling. Then, the top $5 \mathrm{~cm}$ of the sediment core at each site was divided into $0.5-\mathrm{cm}$ slices and the remainder was cut into $1-\mathrm{cm}$ slices. In order to acquire a highenough volume of pore water for the analysis of PAHs, overlying water was taken as a whole without stratification and the fresh sediment core was sectioned in 5-cm slices. All subsamples of fresh slices were centrifuged to obtain pore water 
Fig. 1 Sampling sites of sediment cores from the northern bays and the central part of Taihu Lake

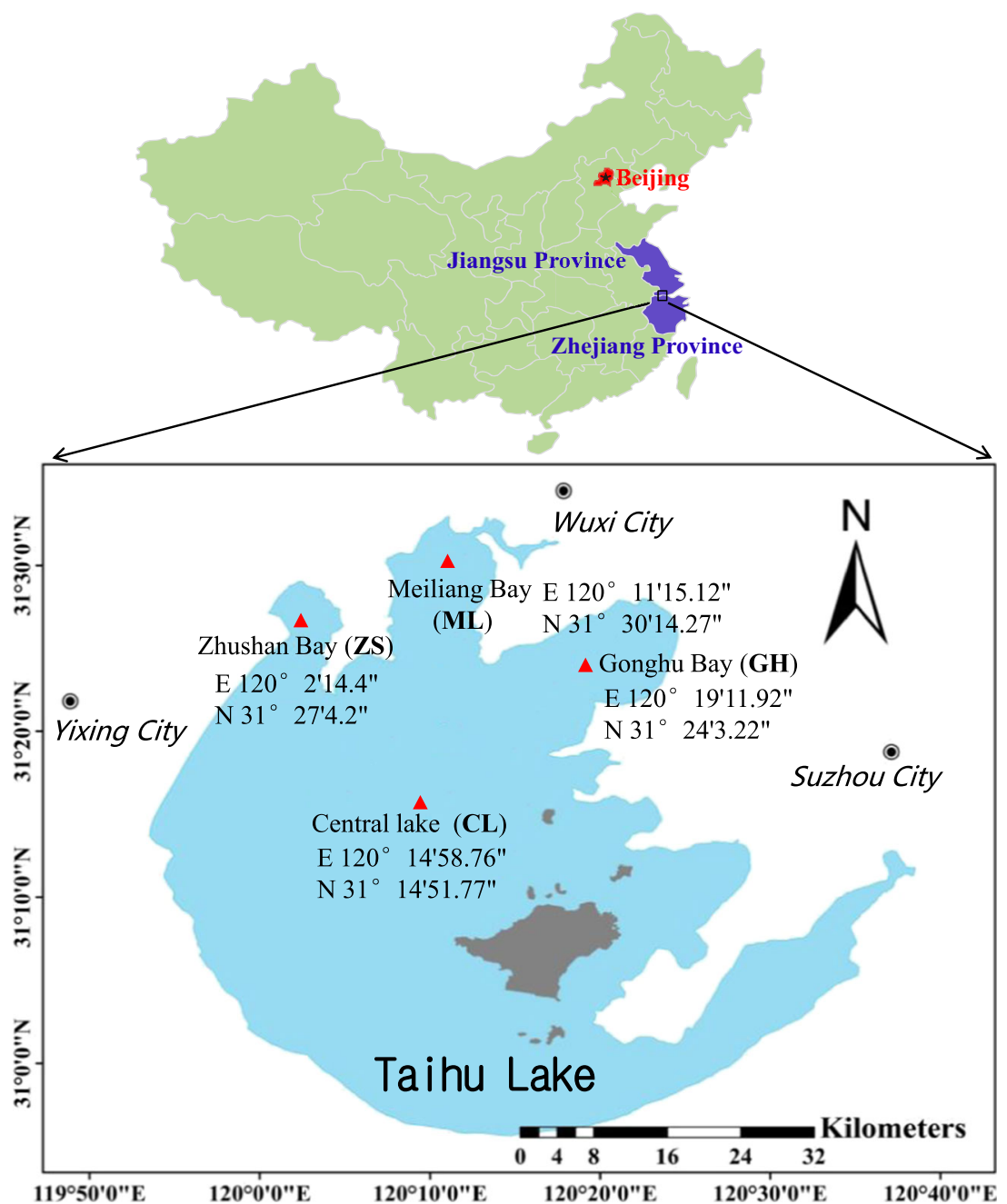

by high-speed centrifugation (4000 rpm for $30 \mathrm{~min}$ ). Both overlying water and pore water samples were filtered and then stored in the dark at $4{ }^{\circ} \mathrm{C}$ until further analysis.

When measuring PAHs in liquid samples, both overlying water and the isolated pore water were concentrated by solidphase extraction (SPE) with Sep-Pak C18 cartridges $(6 \mathrm{~mL}$, $500 \mathrm{mg}$; Waters). The details of this procedure were described in a previous publication (Zhang et al. 2011). Briefly, the cartridges were mounted on a 12-port Visiprep SPE Vacuum Manifold (<20 mmHg vacuum; Supelco, USA). Disposable liners were applied to eliminate the risk of crosscontamination and maintain reproducible extractions by controlling the eluent's flow rate. The $\mathrm{C} 18$ cartridges were preconditioned sequentially by ethyl acetate, methanol, and distilled water (the volume of each solvents were $5 \mathrm{~mL}$ ) prior to use. Filtered liquid samples spiked with surrogates were loaded onto cartridges with vacuum by keeping the flow rate of the eluent close to $8 \mathrm{~mL} \mathrm{~min}^{-1}$ and followed by eluting with $4 \mathrm{~mL}$ of 1:1 dichloromethane/hexanes and $4 \mathrm{~mL}$ of hexanes. The extract was condensed to less than $1 \mathrm{~mL}$ with rotary evaporation, solvent-exchanged to hexanes, and again concentrated to less than $1 \mathrm{~mL}$. Anhydrous sodium sulfate was used to remove water residue. The extract was finally concentrated to $200 \mu \mathrm{L}$ under gentle nitrogen stream for analysis.

\section{Instrumental analysis and quality control and assurance}

The concentrations of five heavy metals $(\mathrm{Cr}, \mathrm{Cu}, \mathrm{Ni}, \mathrm{Pb}$, and $\mathrm{Zn}$ ) were determined by inductively coupled plasma-mass spectrometry (ICP-MS, 7500a; Agilent Technologies, USA) with limits of detection of $0.015-0.120 \mu \mathrm{g} \mathrm{L}^{-1}$. A laboratory quality control system was applied to ensure the validity of the analytical data and the precision of experimental methods, which included reagent blanks and replicate samples. The results of the duplicate analyses demonstrated excellent reproducibility for the method and equipment, and the relative standard deviation was less than $10 \%$.

The following 16 priority PAHs were selected as target compounds in the analysis: naphthalene (Nap), acenaphthylene (Acy), acenaphthene (Ace), fluorene (Fluo), phenanthrene (Phe), anthracene (Ant), fluoranthene (Flua), pyrene (Pyr), 
benzo $[a]$ anthracene $(\mathrm{BaA})$, chrysene (Chry), benzo $[b]$-fluoranthene $(\mathrm{BbF})$, benzo $[k]$ fluoranthene $(\mathrm{BkF})$, benzo- $[a]$ pyrene $(\mathrm{BaP})$, indeno[1,2,3-c, $d]$ pyrene (IncdP), dibenz $[a, h]$-anthracene (DBA), and benzo $[g, h, i]$ perylene (BghiP). Their physical and chemical properties are shown in Table S1. The PAHs were quantified by a Clarus SQ 8 GC-MS (PerkinElmer, USA) equipped with a DB5-MS column (30 $\mathrm{m} \times 0.25 \mathrm{~mm}$ diameter, $0.25 \mu \mathrm{m}$ film thickness). High-purity helium was used as the carrier gas, with a column flow rate of $1.2 \mathrm{~mL} \mathrm{~min}^{-1}$ in constant-flow mode. The temperatures of injector, ion source, and transfer line were 280, 230, and $250{ }^{\circ} \mathrm{C}$, respectively. The GC temperature program was set as follows: initially at $80^{\circ} \mathrm{C}$ for $1 \mathrm{~min}$, increased to $150^{\circ} \mathrm{C}$ at $20{ }^{\circ} \mathrm{C} \mathrm{min}^{-1}$, and held for $6 \mathrm{~min}$, then increased to $250^{\circ} \mathrm{C}$ at $10^{\circ} \mathrm{C} \mathrm{min}^{-1}$ and held for $12 \mathrm{~min}$, finally increased to $290^{\circ} \mathrm{C}$ at $30^{\circ} \mathrm{C} \mathrm{min}^{-1}$, and held for $6 \mathrm{~min}$. The electron impact energy was set at $70 \mathrm{eV}$. One microliter of each sample was injected in splitless mode. A satisfactory separation of the 16 PAH targets could be achieved in total ion chromatogram and in the selected ion monitoring (SIM) mode (Fig. S1). Peak confirmation and quantification of PAHs were analyzed in the SIM mode.

The experiments were subject to strict quality control procedures. Quantification of samples was performed using an external standard method, and the correlation coefficients for the 16 priority PAHs ranged from 0.996 to 0.999 . The PAHs in the blanks were not detected or much lower than the detection limits (1.0-10 ng L $\left.{ }^{-1}\right)$. Besides, samples spiked with known amounts of surrogate standard mixtures (naphthalene-d8, acenaphthene-d10, phenanthrene-d10, chrysene-d12, and perylene-d12) were also measured to estimate the repeatability and accuracy of the analytical method. The values of mean recoveries and the relative standard deviation of surrogates in the water matrixes were $71.8 \pm 3.5 \%$ (naphthalene-d8), $81.3 \pm 8.5 \%$ (acenaphthene-d10), $94.0 \pm 7.3 \%$ (phenanthrene-d10), $89.4 \pm 10.8 \%$ (chrysene-d12), and $88.9 \pm 8.0 \%$ (perylene-d12) $(n=5)$, respectively. The difference between duplicate samples of all target chemicals was less than $15 \%$.

All experimental analyses were conducted in the State Key Laboratory of Environmental Aquatic Chemistry, Research Center for Eco-Environmental Sciences, Chinese Academy of Sciences. This State Key Laboratory was certified by China Metrology Accreditation with certificate no. 2014003240K (validity-September 28, 2014 to September $27,2017)$ to ensure the authenticity of data and present the results for demonstration purposes. Replicate water samples $(n=5)$ spiked with 16 PAH targets using spiked matrix samples were also measured by another certified laboratory (Beijing China Tech Inman Environmental Testing \& Research Center, certificate no. 201410484U). The results showed that the recoveries of PAH compounds of spiked water samples from two certified laboratories were mostly between 80 and $120 \%$ (Fig. S2), which fitted in with the regular recovery range recommended by the USEPA (70-120\%) (USEPA 1996).

\section{Diffusive flux across the sediment-water interface}

Molecular diffusion of contamination across the sedimentwater interface is driven by the chemical concentration gradient, so the diffusive flux of dissolved contaminants from pore water to overlying water can be estimated through Fick's First Law on this assumption (Tro 2001; Campanha et al. 2012).

$F=\varphi \times D_{\mathrm{s}} \times \frac{\partial c}{\partial x}$

where $F\left(\mu \mathrm{g} \mathrm{m}^{-2}\right.$ day $\left.^{-1}\right)$ is the diffusive flux across the sediment-water interface and $\varphi$ (dimensionless) is the porosity of the surface sediment and can be approximately estimated by the water content (Avnimelech et al. 2001). $D_{\mathrm{s}}\left(\mathrm{cm}^{2} \mathrm{~s}^{-1}\right.$ ) is the sediment diffusion coefficient of the species derived from the diffusion coefficient $D_{0}\left(\mathrm{~cm}^{2} \mathrm{~s}^{-1}\right)$ of the species at infinite dilution:

$D_{\mathrm{s}}=\varphi D_{0}(\varphi<0.7)$

$D_{\mathrm{s}}=\varphi^{2} D_{0}(\varphi>0.7)$

The values of $D_{0}$ for five heavy metals were adopted from a previous report (Yuan-Hui and Gregory 1974). $\frac{\partial c}{\partial x}$ $\left(\mu \mathrm{g} \mathrm{L}^{-1} \mathrm{~cm}^{-1}\right.$ ) is the gradient of contamination across the sediment-water interface and can be estimated from pore water profiles with the assumption that the gradient is onedimensional (Kalnejais et al. 2015; Liu et al. 2014).

Unfortunately, the diffusion coefficient of individual PAH was not available, and the vertical resolution of PAHs $(5 \mathrm{~cm})$ across the sediment-water interface was not high enough to quantitatively calculate the diffusive influx at this time.

\section{Toxicity of heavy metals and PAHs in pore water to aquatic organisms}

A water quality index (interstitial water toxicity criteria unit, IWCTU) was applied to examine the toxicity of heavy metals in pore water (Adams et al. 2007):

$\operatorname{IWCT} U_{M e}=\frac{[M e]_{\text {i.w. }}}{F C V_{M e}}$

where $[\mathrm{Me}]_{\mathrm{i} . \mathrm{w} .}$ represents the concentration of the selected heavy metal $(\mathrm{Me})$ in pore water $\left(\mathrm{mg} \mathrm{L}^{-1}\right)$ and $F C V_{M e}$ $\left(\mathrm{mg} \mathrm{L}^{-1}\right)$ is the hardness-dependent final chronic toxicity value for each metal (USEPA 1999; Liu et al. 2003), and this index was calculated by the equations shown in Table S2. The Nemeraw index (NI) was calculated by $\Sigma \mathrm{IWCTU}_{M e}$ to assess the toxicity of heavy metals in pore water. The grade of this toxically risk index could be classified into five ranks, no 
impact, slight impact, moderate impact, strong impact, and serious impact, based on the NI values of $<1,1-2,2-3,3-5$, and 5, respectively (Liu et al. 2003).

$\mathrm{NI}=\left[\frac{\left(\mathrm{IWCTU}_{\max }\right)^{2}-\left(\mathrm{IWCTU}_{\text {mean }}\right)^{2}}{2}\right]^{1 / 2}$

As for PAHs, a hazard quotient was used to evaluate the toxicity of PAHs in pore water. This index was based on the estimated concentration of each PAH in pore water divided by its chronic toxicity value. Hazard quotients for all of the PAHs detected were summed to produce a hazard index (HI) for total PAHs:

$\mathrm{HQ}=(\mathrm{PAH})_{\text {sol }} /$ chronic value

$\mathrm{HI}=\Sigma \mathrm{HQ}$

Chronic toxicity value of individual PAH was adopted from a previous publication (Neff et al. 2005). An HI value greater than 1 indicates that pore water contains concentrations of total PAHs in excess of their estimated chronic toxicity to aquatic organisms (Ozretich et al. 2000).

\section{Statistical analysis}

Two-tailed $t$ test was used to compare the average concentrations between samples in the present study, and the Kolmogorov-Smirnov test for normality was conducted by using the SPSS Statistics 19.0 software. A critical $p$ value of 0.05 was taken to indicate significance. The relationships between the toxicity (NI) and their corresponding concentrations of heavy metals in overlying water and pore water were determined by Origin Pro 8.0 with a linear fitting model. The map of the sediment core sampling sites was produced using Arc GIS 10.0 program.

\section{Results and discussion}

\section{Occurrence and distribution of heavy metals in pore water}

The distribution of heavy metals showed spatial and vertical variability in overlying water and pore water profiles (Fig. 2). Concentrations of heavy metals were basically stable as depth increased in overlying water except for $\mathrm{Cr}$ and $\mathrm{Zn}$ at $\mathrm{ZS}$ and $\mathrm{Zn}$ at $\mathrm{GH}$, both of which showed a tendency to fluctuate across the sediment-water interface. Average concentrations from all four sties varied in the following order: $\mathrm{Zn}$ $\left(40.9 \mu \mathrm{g} \mathrm{L}^{-1}\right)>\mathrm{Cr}\left(11.7 \mu \mathrm{g} \mathrm{L}^{-1}\right)>\mathrm{Pb}\left(10.3 \mu \mathrm{g} \mathrm{L}^{-1}\right) \approx \mathrm{Cu}$ $\left(9.88 \mu \mathrm{g} \mathrm{L}^{-1}\right)>\mathrm{Ni}\left(8.86 \mu \mathrm{g} \mathrm{L}^{-1}\right)$ for overlying water, while the order was $\mathrm{Zn}\left(42.5 \mu \mathrm{g} \mathrm{L}^{-1}\right)>\mathrm{Cu}\left(23.4 \mu \mathrm{g} \mathrm{L}^{-1}\right)>\mathrm{Cr}$ $\left(18.8 \mu \mathrm{g} \mathrm{L}^{-1}\right)>\mathrm{Pb}\left(13.5 \mu \mathrm{g} \mathrm{L}^{-1}\right)>\mathrm{Ni}\left(12.0 \mu \mathrm{g} \mathrm{L}^{-1}\right)$ for surface pore water $(0-3 \mathrm{~cm})$. Concentrations of heavy metals in overlying water were significantly lower than those in pore water $(p<0.05)$. Concentrations of the selected heavy metals in both overlying water and pore water from Taihu Lake were all lower than the standard values of the environmental quality standards for surface water (China EPA 2002).

There were distinct changes in the vertical concentrations of heavy metals in pore water. Also, a degree of fluctuation was found in the concentrations of all metals across the sediment-water interface, indicating that heavy metals could be remobilized in the surface sediment. The concentrations of the majority of heavy metals measured in the pore water profiles, except for $\mathrm{Pb}$ at $\mathrm{ZS}$ and $\mathrm{GH}$, and $\mathrm{Ni}$ and $\mathrm{Zn}$ at $\mathrm{ZS}$, were drastically increased with the increase in sediment depth, and the highest detected concentrations of these heavy metals were recorded between 2 and $5 \mathrm{~cm}$ deep. After the "peak," the concentrations of these heavy metals gradually decrease until they remain constant with little fluctuation in the end of the profiles (Fig. 2).

Even though some differences occurred between sampling sites, in most cases, there were similar trends between all metals and $\mathrm{Mn}$, with coincident maxima in the profiles. Sedimentary diagenetic processes across the sediment-water interface, such as diffusion, migration, and transformation, are significantly driven by redox geochemistry, and $\mathrm{Mn}$ or $\mathrm{Fe}$ could be a good indicator to reveal the status of sedimentary redox conditions (oxic, sub-oxic, or anoxic conditions; Kalnejais et al. 2015). The peaks of Mn in the profiles show that the redox conditions facilitate the reductive dissolution of a fraction of Mn oxyhydroxide particles and their release into pore water (Campanha et al. 2012). The thicknesses of suboxic layers from the northern bays (about $2-3 \mathrm{~cm}$ ) were thinner than that (about $5 \mathrm{~cm}$ ) at the central lake (CL) site. This distribution may be attributed to the good hydrological conditions at $C L$ with a broader field of open water, which provides higher oxygenation in the water column and consequently increases oxygen penetration into the sediment (Scholz et al. 2011).

The profiles of most sampling sites showed relatively high concentrations of all heavy metals in the surface pore water, which might result from the co-precipitation or adsorption of metals with $\mathrm{Fe}$ or Mn oxyhydroxides in the oxic and sub-oxic layer (Álvarez-Iglesias and Rubio 2008; Santos-Echeandia et al. 2009). Due to reductive dissolution, metals were released into pore water and higher metal concentrations were recorded in these layers (Caetano et al. 2007). The maximum values of the majority of metals occurred between 2 and $5 \mathrm{~cm}$ deep in the sediments, which is also consistent with the concentrations of $\mathrm{Mn}$ in the corresponding profiles.

In a similar way for the pore water profiles, both heavy metals and Mn showed a decreasing trend beneath the suboxic layers, and this is probably due to the metals being precipitated with sulfides or immobilized by adsorption to particles (from the co-precipitation of Fe with sulfides to form 

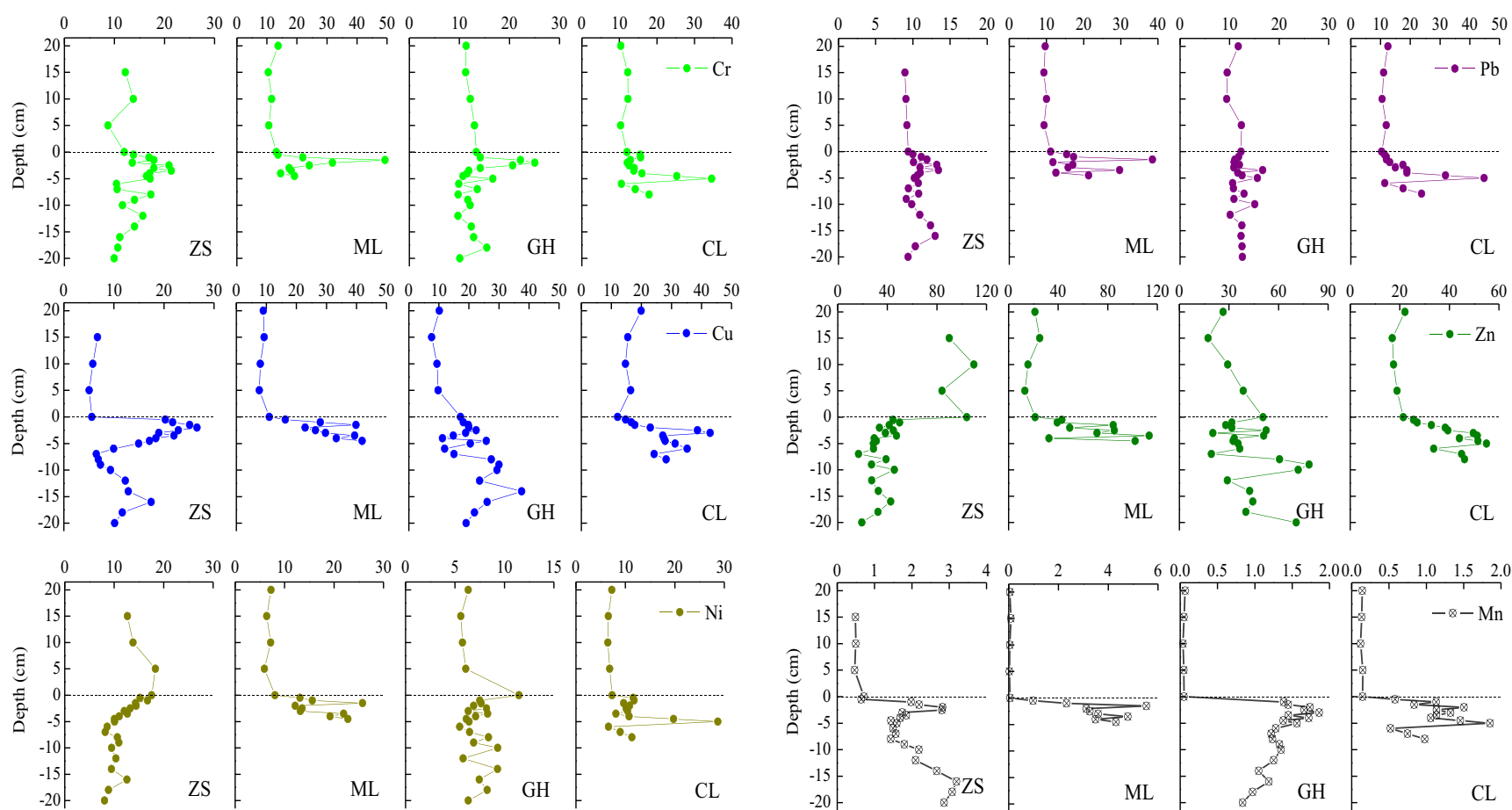

Fig. 2 Profiles of heavy metals and Mn in pore water and overlying water from the northern bays of Taihu Lake (the dashed lines represent the sedimentwater interface)

pyrite, $\mathrm{FeS}_{2}$ ) under the anoxic conditions at these depths (Álvarez-Iglesias and Rubio 2008).

However, some specific heavy metal profiles, such as $\mathrm{Pb}$ at ZS and GH, showed a different pattern. The metal concentrations in these profiles were nearly constant with depth, which is totally different from the $\mathrm{Mn}$ profiles. The profiles of $\mathrm{Ni}$ and $\mathrm{Zn}$ at $\mathrm{ZS}$ showed concentrations progressively decreasing from top to bottom without showing layers of pronounced spikes in concentrations. Thus, these characteristics may be attributed to some other factors such as $\mathrm{pH}$, redox conditions, sulfide concentration, occurrence of complexants, and dissolved organic carbon, which may have controlled the mobility of metals in the deeper layer of pore water, and these processes needed further research to identify other processes that govern metal mobility (Campanha et al. 2012; Point et al. 2007).

The metal concentration profiles showed differences between different bays and the central lake of Taihu Lake. The average concentrations of most metals were highest at ZS for overlying water, while the maximum concentrations were observed at ML for pore water, which was consistent with a previous report (Tao et al. 2012). This variation may be ascribed to the influence of anthropogenic activity on sedimentary heavy metals since these two bays have received large amounts of municipal sewage and industrial waste water from several input rivers (such as the Taige Canal and Wangyu River) (Qu et al. 2002). Particles were transported from input rivers and deposited in the estuaries caused by the hydrodynamic changes. Heavy metals had high affinity toward the organic matter in these particles, and this situation led to higher concentrations of most metals in these two sections (Pérez-Esteban et al. 2014).

\section{Diffusive fluxes of heavy metals across the sediment-water interface}

The average fluxes of $\mathrm{Cr}, \mathrm{Cu}, \mathrm{Ni}, \mathrm{Pb}$, and $\mathrm{Zn}$ in the north bays of Taihu Lake were 27.3, 24.8, 7.03, 7.81, and $-3.32 \mu \mathrm{g}\left(\mathrm{m}^{2}\right.$ day $)^{-1}$, respectively, indicating export from sediment into overlying water with the exception of Zn (Fig. 3). The absolute flux values of all five metals at $\mathrm{CL}$ were much lower than those in the northern bays of Taihu Lake, which could be attributed to the absence of peak concentrations of metals in sub-oxic zones in the profiles. It is worth mentioning that the areas around $\mathrm{CL}$ are open water bodies with a large surface area, and those differences were reflected in pore water and the fluxes.

The diffusive flux values of $\mathrm{Cu}$ at $\mathrm{ZS}$ and $\mathrm{ML}$ both exceed $50 \mu \mathrm{g}\left(\mathrm{m}^{2} \text { day }\right)^{-1}$; in addition, $\mathrm{Cu}$ was found to be released from sediment to overlying water in all bays, which may potentially pose health risks to the aquatic organisms and the surface water. At ZS, as well as ML, the highest fluxes were observed for most of the heavy metals where the metal concentrations in pore water were higher and showed peaks in the sub-oxic zone. The release fluxes of some heavy metals (such as $\mathrm{Cr}$ at $\mathrm{ZS}$ ) were very high even though pore water did not have the highest concentrations. This characteristic may be explained by the discharge of leather industry wastewater at 


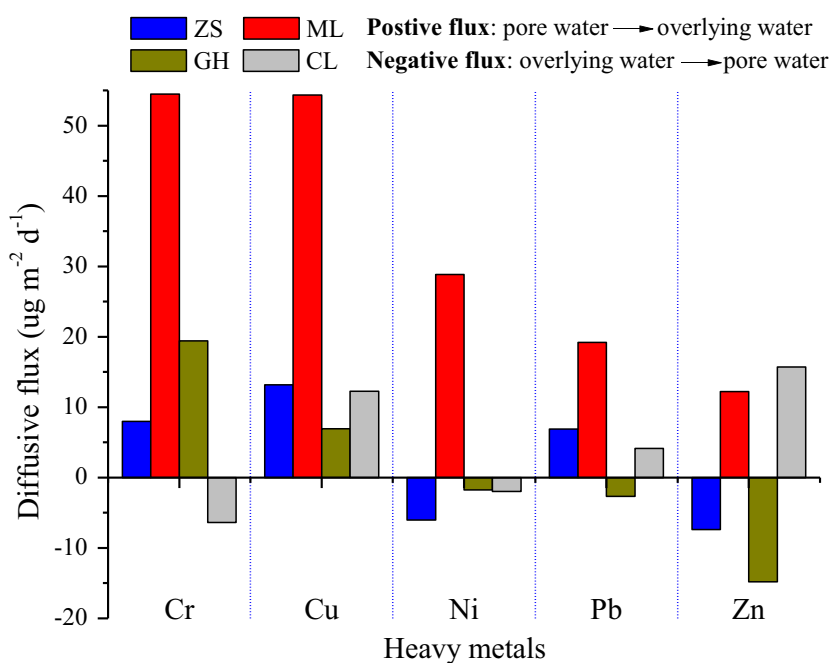

Fig. 3 Diffusive fluxes of heavy metals across the sediment-water interface from the northern bays of Taihu Lake

this site, and the sediments have become important pollution sources of heavy metals (Tao et al. 2012).

The estimations of metal diffusive flux show the extent to which sediments can act as a source or sink for metals in the aquatic systems. The range and average diffusive flux of selected heavy metals are summarized in Table 1, and some reported values from some lakes in China and other countries are also shown for comparison purposes. Among all areas, the diffusive fluxes of $\mathrm{Cr}$ and $\mathrm{Cu}$ in the northern bays of Taihu Lake were the highest. The diffusive fluxes of $\mathrm{Ni}$ and $\mathrm{Pb}$ were comparable to the lakes in China (such as Shahe Reservoir and Dianchi Lake), which were heavily polluted by heavy metals from their input rivers (Yuan et al. 2014; Li et al. 2008). Compared with the reports on other aquatic environments around the world listed in Table 1, the diffusive influxes from the northern bays of Taihu Lake, with the exception of $\mathrm{Zn}$, were generally close to the values of some industrial area or severely impacted urban estuary, including Deule River in France (Lourino-Cabana et al. 2012), Lake Hope and San Francisco Bay in USA (López et al. 2010; RiveraDuarte and Russell Flegal 1997), Vigo Ria in Spain (Santos-Echeandia et al. 2009), and the Lagoon of Venice in Italy (Turetta et al. 2005). The accumulation of heavy metals in sediment, which is mostly linked to anthropogenic activities, may lead to higher fluxes across the sediment-water interface. The Taihu Lake Basin, as well as Eastern China, has experienced rapid economic development with the implementation of the Reform and Open Policy since the late 1970s. Large amounts of wastewater from industries such as paper-making, leather, electro-plating, and metallurgy were discharged to the lake through input rivers, resulting in increasing metal pollution and relatively higher diffusive influxes in sediments (Liu et al. 2004; Tao et al. 2012).

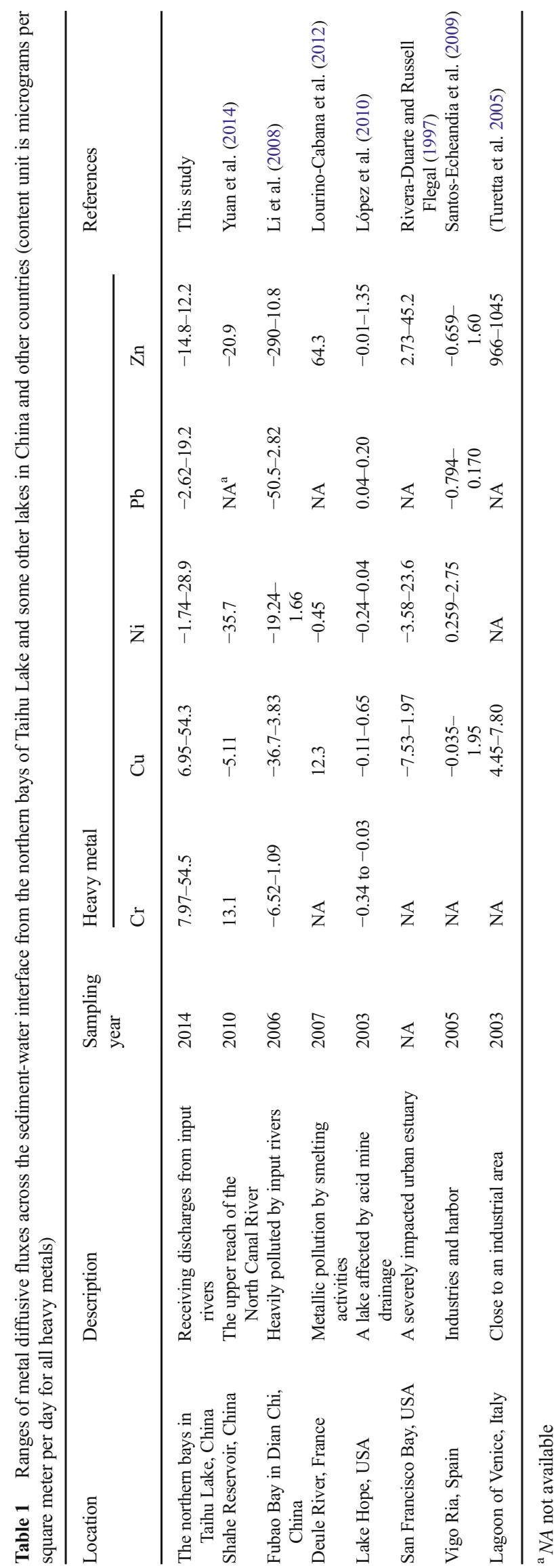


Toxicity and risk assessment of heavy metals in pore water

The freely dissolved concentration of a contaminant is actually bioavailable in aquatic systems so that the toxicity of heavy metals depends more on their dissolved concentrations in pore water rather than those in sediments (Escher and Hermens 2004). The IWCTU values of $\mathrm{Pb}$ exceeded 1 at all sites, as well as that for $\mathrm{Cu}$ in some of the pore water samples, which implies that these two heavy metals may have potential risks of toxicity to aquatic organisms. The total IWCTU ( $\Sigma$ IWCTU) values in all profiles at four sites also exceeded 1, with higher values in deeper sediments, indicating that there is a potential toxic risk from multiple heavy metals at these sites (Table S3). The NI values of overlying water from three northern bays and the central lake (CL) ranged from 1 to 2 (slight impact) and 2 to 3 (moderate impact), respectively. The potential metal toxicity occurred dangerously near the surface sediments (Fig. 4). Similar to the concentrations of heavy metals in pore water, the NI values in the profiles reached their maxima (mostly worse than strong impact) in the surface pore water $(\sim 1-3 \mathrm{~cm})$, which is probably due to the release of heavy metals from biogenic material during the aerobic degradation of organic matter in this layer (Gavriil and Angelidis 2006). In contrast, the NI values in deeper layers significantly decreased with depth and reached values approximately equal to those in overlying water, which is probably due to the formation of authigenic minerals in the buried sediment by sulfides and/or carbonates through reaction with these heavy metals (Lesven et al. 2010).

The highest NI value in surficial pore water of sediments was found to be greater than 8 at CL, which was far above the values at the three bays. However, this result was quite different from the potential ecological risk of heavy metals in sediments based on spatial distribution in previous reports (Tao et al. 2012; Yuan et al. 2011). This seeming contradiction indicated that a relatively high total concentration of heavy metals in polluted sediment may not cause a serious situation, while higher concentrations and bioavailability of heavy metals in pore water could pose a considerable potential risk. In our findings, the toxicity of heavy metals in pore water corresponded well to their concentrations, especially for the dominant contributor $(\mathrm{Pb})$ to the $\Sigma$ IWCTU $\left(R^{2}=0.9303\right.$, $p<0.001$, Fig. S3). Physical, chemical, or even biological factors (e.g., hydrological conditions, hardness, redox condition, the mineralization process of organic matter) would significantly influence the concentrations, distribution, bioavailability, and toxicity of heavy metals in pore water (Luff and Moll 2004; Lourino-Cabana et al. 2011). Thus, comprehensive investigations that include both the total metal risk in sediments and the toxicity of bioavailable fraction in pore water are recommended when assessing the risk of heavy metals in aquatic environments.

\section{Profiles of PAHs in pore water}

The total concentration of the $16 \mathrm{PAHs}$ in surface pore water $(0-5 \mathrm{~cm})$ ranged from $1582(\mathrm{CL})$ to $3030(\mathrm{ML}) \mathrm{ng} \mathrm{L}^{-1}$, which is 5 to 16 times higher than that in overlying water, with a mean value of $2867 \mathrm{ng} \mathrm{L}^{-1}$. The profiles of total PAHs were all sharply increased from overlying water to pore water, indicating a potential flux of PAHs from sediment to overlying water. According to compositions of PAHs in different sampling sites, 2- and 3-ring PAHs accounted for 88-92\%, 4-ring PAHs for 7-11 \%, and 5-6-ring PAHs less than $2 \%$, respectively, of the total PAHs in overlying water. Moreover, 2- and 3-ring PAHs also dominated the PAH distributions in pore water, with an average proportion of $53 \%$ (Fig.5).

PAHs were a typical kind of hydrophobic organic compounds (HOCs), which have high $K_{\text {ow }}$ values and low aqueous solubility (Table S1). The presence of dissolved organic colloids enhances the aqueous concentrations of PAHs significantly beyond their solubilities (Nam and Alexander 1998). The maximum PAH concentrations in pore water were recorded at about 10 to $25 \mathrm{~cm}$ depth that corresponded to the maximum sedimentary PAH concentrations at nearly the same depth (unpublished data). Similar trends were also observed by other investigations (Gao et al. 1998; McGroddy and Farrington 1995). The concentrations of total PAHs in pore water were correlated with the DOC contents. This kind of "solubilization effect" is especially effective for high molecular weight PAHs which are nonpolar and have high $K_{\text {ow }}$ values. In aquatic systems, PAHs are distributed mainly among three phases: the truly dissolved PAHs, the DOC-
Fig. 4 The profiles of the Nemeraw index (NI) across the sediment-water interface from the northern bays of Taihu Lake (the dashed lines represent the sediment-water interface)

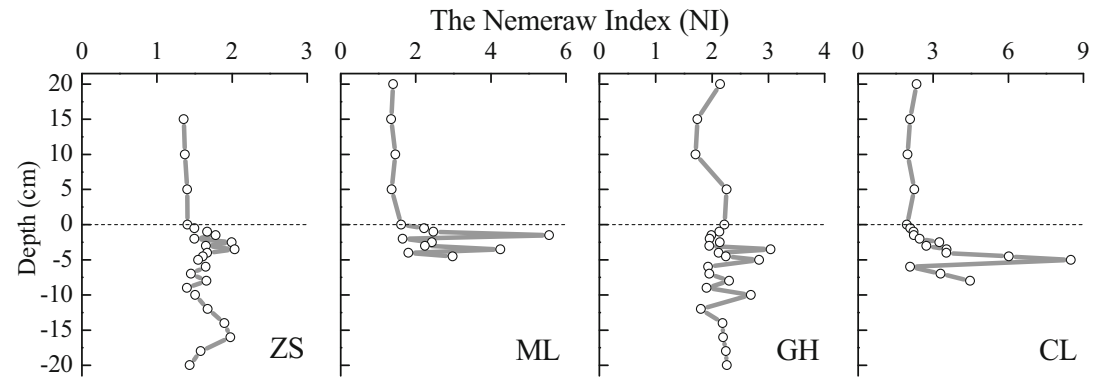

NI values: no impact $(<1)$, slight impact (1-2), moderate impact (2-3), strong impact (3-5), and serious impact $(>5)$ 

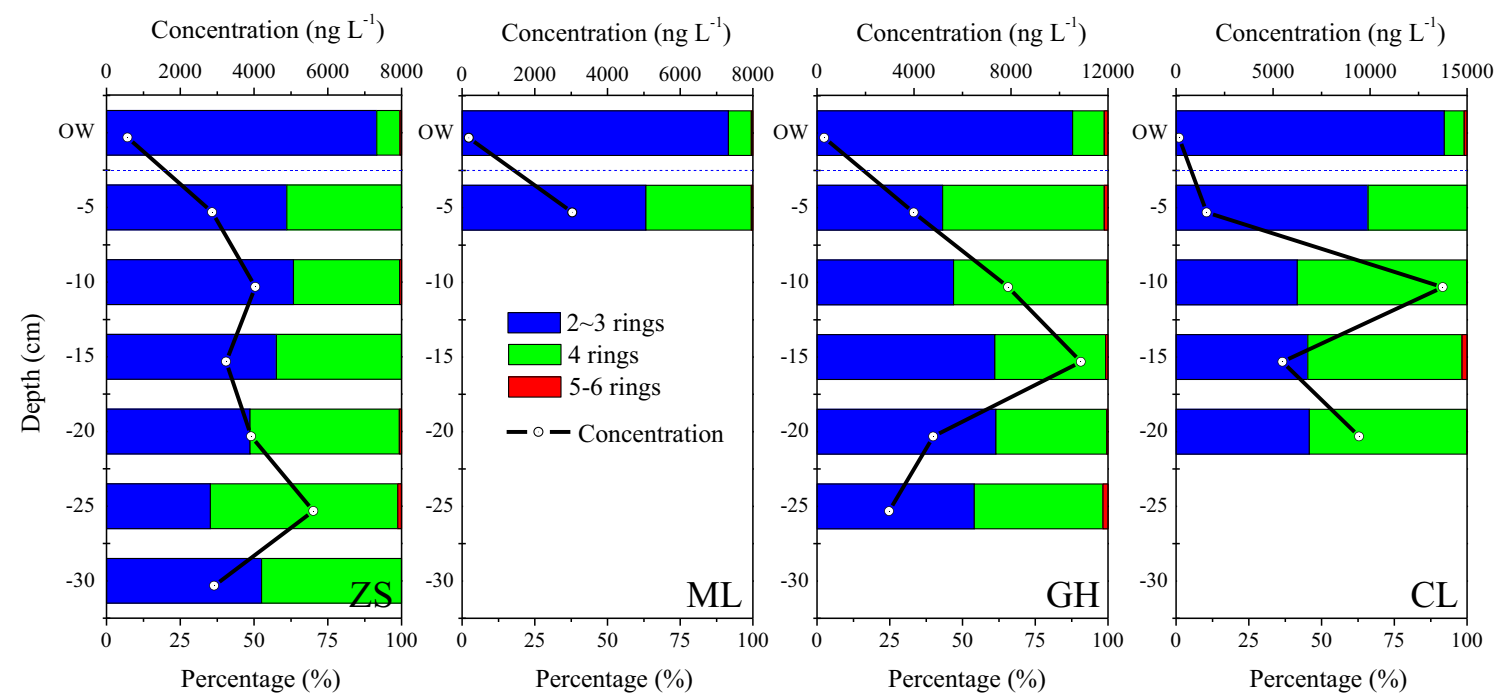

Fig. 5 Profiles of concentrations and percentages of PAHs in overlying water $(\mathrm{OW})$ and pore water (the dashed lines represent the sediment-water interface)

bounded PAHs, and the PAHs in the solid sediments (Hegeman et al. 1995). With increasing DOC in pore water, more PAHs would be sorbed by DOC with the consequence of increasing PAH concentration in pore water, according the $K_{\mathrm{oc}}$ value decreases (Gao et al. 1998). The absence of high molecular weight PAHs in pore water $\left(<5 \mathrm{ng} \mathrm{L}^{-1}\right)$ is indicative of the strong binding of these PAHs to the solid matters. The distribution and concentration of PAHs in pore water are not just only controlled by the solubility of the individual compounds, which may be also attributed to sediment properties or "aged " PAHs (hysteresis), etc. In addition, different DOC properties (such as components, ionic strength, or salt effect) in pore water would also result in different patterns of PAH in these phases (Lassen and Carlsen 1997). These processes need further study within more comprehensive experiments in the laboratory or on situ. Also, high-resolution methods (such as solid-phase microextraction, SPME; passive sampling) are necessary to understand the environmental bioavailability and fate of PAHs in the sediment-water interface in future studies.

\section{Toxicity of PAHs in overlying water and surface pore water}

PAHs in aqueous environmental samples (such as surface water, overlying water, or pore water) are considered to be much more toxic and biologically available to the aquatic organisms than sedimentary PAHs (Gustafsson et al. 1997). Therefore, a hazard index (HI) was used here to evaluate the toxicity of PAHs in overlying water and surface pore water $(0-5 \mathrm{~cm})$. The hazard quotient (HQ) and hazard index (HI) of PAHs were calculated from Eq. (6) and (7), and the values are shown in Fig. 6. Taking the toxicity values as reference, the HI values ranged from
0.008 to 0.027 , with an average of 0.018 in overlying water at four sites, indicating no or low ecological risk in overlying water of Taihu Lake. The average value of HI in surface pore water was 0.63 , which also showed no or low ecological risk. However, the values were 18 to 63 times higher than their corresponding values in overlying water. Moreover, a notably high HI value (1.19) was found in surface pore water at $\mathrm{GH}$, indicating that pore water in this site could pose a toxic risk to the benthic fauna at this site.

As for the contributions of $\mathrm{HI}$ values of individual $\mathrm{PAH}$, several PAHs (such as Phe, BaA, Chry, BbF, and Incdp) contributed equally (about $10 \%$ ) to the hazard quotient in terms of chronic value, while others' contributions were all less than $5 \%$ (Fig. 6). In surface pore water, $\mathrm{BkF}, \mathrm{BbF}$, and $\mathrm{DBA}$ were the dominant contributors to the toxic-response factor for $\mathrm{HI}$ values $(50.8,30.3$, and $10.2 \%$ on average, respectively). The main contributors of the above PAH (except Phe) were all carcinogenic PAHs with higher toxic equivalence factors according to the data from USEPA (Nadal et al. 2004). Therefore, these individual PAHs should be given high attention and taken as the priority contaminants for control measures.

Probabilistic risk assessment is an important tool for environmental managers to identify and prioritize PAHs for aquatic environment (Guo et al. 2012; Schuler et al. 2008). However, the Kolmogorov-Smirnov test for normality was conducted and the results showed that some distributions of individual PAH in the present study, especially for carcinogenic ones (BaP, IncdP, DBA, etc.) with higher toxic equivalence factors, were not normal $(p>0.05$, Table S4). Therefore, enough data with normal distribution are needed to achieve the probabilistic risk assessment for screening and ranking the risk to aquatic 
Fig. 6 The hazard index (HI) values and contribution of different PAHs for toxic-response factor in overlying water $(\mathrm{OW})$ and surficial pore water (PW, 0-5 cm) from the northern bays of Taihu Lake

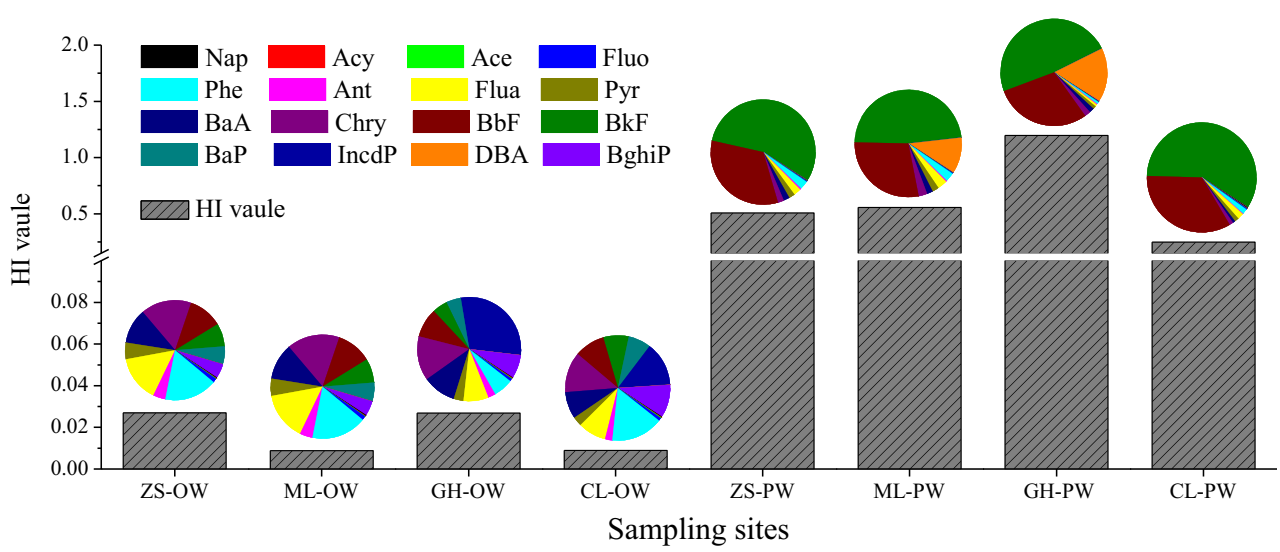

organisms in a further study. Here, the relative frequency of the hazard index (HI) values in the profiles of overlying water and pore water is presented in Fig. S5. Obviously, benthic organisms in deeper layers would be adversely affected because all samples in deeper pore water had HI values higher than 1 .

As shown in Fig. 6, the concentrations of 16 individual PAH were all below their corresponding chronic toxicity values (Table S1), and the average values of $\mathrm{HI}$ in overlying water and surface pore water were both less than 1 , showing no or low potential ecological risk for Taihu Lake. However, these results do not mean the outlook is optimistic. Our finding indicated that concentrations of PAHs in surface pore water were higher than those in overlying water, exhibiting a positive flux of PAHs from pore water to overlying water. There may be an occasional risk according to the HI values of PAHs in surface pore water at $\mathrm{GH}$, and the carcinogenic ones $(\mathrm{BkF}, \mathrm{BbF}$, and DBA) made the dominant contribution to the toxicity of PAHs in pore water (Fig. 6). Since PAHs in pore water are considered to be more toxic and biologically available to the aquatic organisms than those in sediments, PAHs in pore water would pose a "potential toxicological risk" to human health, especially in the areas that have drinking water works. Besides, Taihu Lake is a typical shallow lake and the sediments are easily re-suspended due to windwave action, leading to a more drastic exchange of pollutants between pore water and overlying water. Many contaminants have been reported in Taihu Lake in recent years (Wang et al. 2003; Zhang and Jiang 2005), and most of them just focused on their environmental occurrence or toxicity assessment in the sediments. Limited data were available on the distribution or toxicity of the coexistent contaminants in pore water to understand their environmental bioavailability and fate in the sediment-water system of the lake. Therefore, the comprehensive toxic effects of these contaminants in pore water should be given priority attention in a further study to obtain an accurate assessment of the safety of Taihu Lake.

\section{Conclusions}

The distribution, diffusive fluxes, and toxicity of 5 heavy metals and 16 priority PAHs in pore water profiles from the northern bays of Taihu Lake were investigated. In all cases, the concentrations of the selected heavy metals in both overlying water and pore water from Taihu Lake did not exceed the standard values of the environmental quality standards for surface water. The concentrations of heavy metals increased as the pore water depth increased, and the highest detected concentrations were recorded between 3 and $5 \mathrm{~cm}$ below the sediment surface. The diffusive fluxes across the sediment-water interface indicated that sediments in the northern bays acted as sources of heavy metals to the water columns. The relatively high diffusive flux of $\mathrm{Cu}$ suggests that pore water could be a direct source of $\mathrm{Cu}$ to overlying water in the study area. The total IWCTU and NI values showed that heavy metals in pore water had a slight to moderate impact on sediment-dwelling organisms. Concentrations of PAHs in surface pore water were higher than those in overlying water, exhibiting a positive flux of PAHs from pore water to overlying water. Concentrations of 16 individual PAH were all below their corresponding chronic toxicity values, and the average HI values showed no or low potential ecological risk for Taihu Lake. While there may be an occasional risk due to the HI values in some pore water greater than 1 , the carcinogenic ones ( $\mathrm{BkF}, \mathrm{BbF}$, and $\mathrm{DBA}$ ) made the dominant contribution to the toxicity of PAHs in pore water. It could be concluded that heavy metals and PAHs in pore water from Taihu Lake may have a potential biological impact but cause no impairment at present. Heavy metals and PAHs and their comprehensive toxic effects in pore water should be given priority attention when developing effective strategies for risk management in this region.

Acknowledgments We are deeply grateful to our colleague Xuehong Kong and Shou Yuan for the sample collection and Dr. Wenzhong Tang for his invaluable advice. This work was supported by the Major Science 
and Technology Program for Water Pollution Control and Treatment (2012ZX07101-002-03) and the National Natural Science Foundation of China (No. 21547009).

\section{References}

Adams RG, Lohmann R, Fernandez LA, et al. (2007) Polyethylene devices: passive samplers for measuring dissolved hydrophobic organic compounds in aquatic environments. Environ Sci Technol 41(4): 1317-1323. doi:10.1021/es0621593

Álvarez-Iglesias P, Rubio B (2008) The degree of trace metal pyritization in subtidal sediments of a mariculture area: application to the assessment of toxic risk. Mar Pollut Bull 56(5):973-983. doi:10.1016/j. marpolbul.2008.01.026

Avnimelech Y, Ritvo G, Meijer LE, et al. (2001) Water content, organic carbon and dry bulk density in flooded sediments. Aquac Eng 25(1): 25-33. doi:10.1016/S0144-8609(01)00068-1

Caetano M, Madureira MJ, Vale C (2007) Exchange of Cu and Cd across the sediment-water interface in intertidal mud flats from Ria Formosa (Portugal). Hydrobiologia 587(1):147-155. doi:10.1007 /s10750-007-0673-y

Campanha MB, Moreira AB, Bisinoti MC (2012) Metal fluxes at the sediment-water interface in rivers in the Turvo/Grande drainage basin, São Paulo state, Brazil. J Soils Sediments 12(10):1508 1516. doi:10.1007/s11368-012-0591-0

China, EPA (2002) Environmental Quality Standards for Surface Water (GB 3838-2002) (in Chinese)

Escher BI, Hermens JLM (2004) Peer reviewed: internal exposure: linking bioavailability to effects. Environ Sci Technol 38(23): 455A-4462. doi:10.1021/es0406740

Gao JP, Maguhn J, Spitzauer P, et al. (1998) Distribution of polycyclic aromatic hydrocarbons (PAHs) in pore water and sediment of a small aquatic ecosystem. Int J Environ Anal Chem 69(3):227-242. doi:10.1080/03067319808032589

Gao B, Zhou H, Yu Y, et al. (2015) Occurrence, distribution, and risk assessment of the metals in sediments and fish from the largest reservoir in China. RSC Adv 5:60322-60329. doi:10.1039/c5 ra09220e

Gavriil AM, Angelidis MO (2006) Metal diagenesis in a shallow semienclosed marine system in the Aegean Sea, Greece. Estuar Coast Shelf S 70(3):487-498. doi:10.1016/j.ecss.2006.06.029

Guo GH, Wu FC, He HP, et al. (2012) Characterizing ecological risk for polycyclic aromatic hydrocarbons in water from Lake Taihu, China. Environ Monit Assess 184:6815-6825. doi:10.1007/s10661-011$2460-5$

Gustafsson Ö, Gschwend PM, Buesseler KO (1997) Using 234 Th disequilibria to estimate the vertical removal rates of polycyclic aromatic hydrocarbons from the surface ocean. Mar Chem 57(1):1123. doi:10.1016/S0304-4203(97)00011-X

Harmsen J (2007) Measuring bioavailability: from a scientific approach to standard methods. J Environ Qual 36(5):1420-1428. doi:10.2134 /jeq2006.0492

Hegeman WJM, Der Weijden CH, Loch JPG (1995) Sorption of benzo[a]pyrene and phenanthrene on suspended harbor sediment as a function of suspended sediment concentration and salinity: a laboratory study using the cosolvent partition coefficient. Environ Sci Technol 29(2):363-371. doi:10.1021/es00002a012

Kalnejais LH, Martin WR, Bothner MH (2015) Porewater dynamics of silver, lead and copper in coastal sediments and implications for benthic metal fluxes. Sci Total Environ 517:178-194. doi:10.1016 /j.scitotenv.2015.02.011
Lassen P, Carlsen L (1997) Solubilization of phenanthrene by humic acids. Chemosphere 34(4):817-825. doi:10.1016/S0045-6535(97 )00010-6

Lesven L, Lourino-Cabana B, Billon G, et al. (2010) On metal diagenesis in contaminated sediments of the Deûle river (northern France). Appl Geochem 25(9):1361-1373. doi:10.1016/j. apgeochem.2010.06.007

Li B, Ding S, Fan C, et al. (2008) Estimation of diffusion fluxes on trace heavy metals at sediment-water interface in Fubao Bay of Dianchi Lake. Environ Chem 27(6):800-804 in Chinese

Liu WX, Coveney RM, Chen JL (2003) Environmental quality assessment on a river system polluted by mining activities. Appl Geochem 18(5):749-764. doi:10.1016/S0883-2927(02)00155-5

Liu EF, Shen J, Zhu YX, et al. (2004) Heavy metals and nutrients pollution in sediments of Taihu Lake. Acta Sedimentol Sin 22:507-512 . doi:10.14027/j.cnki.cjxb.2004.03.020in Chinese

Liu G, Zhang G, Jin Z, et al. (2009) Sedimentary record of hydrophobic organic compounds in relation to regional economic development: a study of Taihu Lake, East China. Environ Poll 157(11):2994-3000. doi:10.1016/j.envpol.2009.05.056

Liu HH, Bao LJ, Zeng EY (2014) Recent advances in the field measurement of the diffusion flux of hydrophobic organic chemicals at the sediment-water interface. TRAC-Trend Anal Chem 54:56-64. doi:10.1016/j.trac.2013.11.005

López DL, Gierlowski-Kordesch E, Hollenkamp C (2010) Geochemical mobility and bioavailability of heavy metals in a lake affected by acid mine drainage: Lake Hope, Vinton County, Ohio. Water Air Soil Poll 213(1-4):27-45. doi:10.1007/s11270-010-0364-6

Lourino-Cabana B, Lesven L, Charriau A, et al. (2011) Potential risks of metal toxicity in contaminated sediments of Deûle river in Northern France. J Hazard Mater 186(2):2129-2137. doi:10.1016/j. jhazmat.2010.12.124

Lourino-Cabana B, Lesven L, Billon G, et al. (2012) Benthic exchange of sedimentary metals $(\mathrm{Cd}, \mathrm{Cu}, \mathrm{Fe}, \mathrm{Mn}, \mathrm{Ni}$ and $\mathrm{Zn})$ in the Deûle River (Northern France). Environ Chem 9(5):485-494. doi:10.1071 /EN12046

Luff R, Moll A (2004) Seasonal dynamics of the North Sea sediments using a three-dimensional coupled sediment-water model system. Cont Shelf Res 24(10):1099-1127. doi:10.1016/j.csr.2004.03.010

McGroddy SE, Farrington JW (1995) Sediment porewater partitioning of polycyclic aromatic hydrocarbons in three cores from Boston Harbor, Massachusetts. Environ Sci Technol 29(6):1542-1550. doi:10.1021/es00006a016

Nadal M, Schuhmacher M, Domingo JL (2004) Levels of PAHs in soil and vegetation samples from Tarragona County, Spain. Environ Poll 132(1):1-11. doi:10.1016/j.envpol.2004.04.003

Nam K, Alexander M (1998) Role of nanoporosity and hydrophobicity in sequestration and bioavailability: tests with model solids. Environ Sci Technol 32(1):71-74. doi:10.1021/es9705304

Neff JM, Stout SA, Gunster DG (2005) Ecological risk assessment of polycyclic aromatic hydrocarbons in sediments: identifying sources and ecological hazard. Integr Environ Assess Manage 1(1):22-33. doi:10.1897/IEAM 2004a-016.1

Ozretich RJ, Ferraro SP, Lamberson JO, et al. (2000) Test of $\Sigma$ polycyclic aromatic hydrocarbon model at a creosote-contaminated site, Elliott Bay, Washington, USA. Environ Toxicol Chem 19(9):2378-2389. doi: $10.1002 /$ etc. 5620190931

Pérez-Esteban J, Escolástico C, Masaguer A, et al. (2014) Soluble organic carbon and $\mathrm{pH}$ of organic amendments affect metal mobility and chemical speciation in mine soils. Chemosphere 103:164-171. doi:10.1016/j.chemosphere.2013.11.055

Point D, Monperrus M, Tessier E, et al. (2007) Biological control of trace metal and organometal enthic fluxes in a eutrophic lagoon (Thau lagoon, Mediterranean Sea, France). Estuar Coast Shelf S 72:457471. doi:10.1016/j.ecss.2006.11.013 
Polizzotto ML, Kocar BD, Benner SG, et al. (2008) Near-surface wetland sediments as a source of arsenic release to ground water in Asia. Nature 454(7203):505-508. doi:10.1038/nature07093

Qin B, Xu P, Wu Q, et al. (2007) Environmental issues of lake Taihu, China. Hydrobiologia 581(1):3-14. doi:10.1007/s10750-006-0521-5

Qu W, Mike D, Fan C, et al. (2002) Distribution, sources and potential toxicological significance of polycyclic aromatic hydrocarbons (PAHs) in Taihu Lake sediments, China. Hydrobiologia 485(1-3): 163-171. doi:10.1023/A:1021301909296

Rivera-Duarte I, Russell Flegal A (1997) Porewater gradients and diffusive benthic fluxes of $\mathrm{Co}, \mathrm{Ni}, \mathrm{Cu}, \mathrm{Zn}$, and $\mathrm{Cd}$ in San Francisco Bay. Croat Chem Acta 70(1):389-417

Santos-Echeandia J, Prego R, Cobelo-García A, et al. (2009) Porewater geochemistry in a Galician Ria (NW Iberian Peninsula): implications for benthic fluxes of dissolved trace elements $(\mathrm{Co}, \mathrm{Cu}, \mathrm{Ni}, \mathrm{Pb}, \mathrm{V}, \mathrm{Zn})$. Mar Chem 117(1):77-87. doi:10.1016/j.marchem.2009.05.001

Scholz F, Hensen C, Noffke A, et al. (2011) Early diagenesis of redoxsensitive trace metals in the Peru upwelling area-response to ENSOrelated oxygen fluctuations in the water column. Geochim Cosmochim Acta 75(22):7257-7276. doi:10.1016/j.gca.2011.08.007

Schuler LJ, Hoang TC, Rand GM (2008) Aquatic risk assessment of copper in freshwater and saltwater ecosystem of South Florida. Ecotoxicology 17(7):642-659. doi:10.1007/s10646-008-0236-7

Tao Y, Yao S, Xue B, et al. (2010) Polycyclic aromatic hydrocarbons in surface sediments from drinking water sources of Taihu Lake, China: sources, partitioning and toxicological risk. J Environ Monit 12(12):2282-2289. doi:10.1039/C0EM00144A

Tao Y, Yuan Z, Wei M, et al. (2012) Characterization of heavy metals in water and sediments in Taihu Lake, China. Environ Monit Assess 184(7):4367-4382. doi:10.1007/s10661-011-2270-9

Tro DMD (2001) Sediment flux modeling. John Wiley, New York

Turetta C, Capodaglio G, Cairns W, et al. (2005) Benthic fluxes of trace metals in the lagoon of Venice. Microchem J 79(1):149-158. doi:10.1016/j.microc.2004.06.003
USEPA (1996) EPA Method 8000B http://www.epa.gov/wastes/hazard/ testmethods/sw846/pdfs/8000b.pdf

USEPA (1999) Recommended Water Quality Criteria-Correction. vol EPA 822-Z-99-001

Von der Heyden CJ, New MG (2004) Sediment chemistry: a history of mine contaminant remediation and an assessment of processes and pollution potential. J Geochem Explor 82(1):35-57. doi:10.1016/j. gexplo.2003.11.001

Wang H, Wang C, Wu W, et al. (2003) Persistent organic pollutants in water and surface sediments of Taihu Lake, China and risk assessment. Chemosphere 50(4):557-562. doi:10.1016/S00456535(02)00484-8

Yuan HZ, Shen J, Liu EF, et al. (2011) Assessment of nutrients and heavy metals enrichment in surface sediments from Taihu Lake, a eutrophic shallow lake in China. Environ Geochem Health 33(1):67-81. doi:10.1007/s10653-010-9323-9

Yuan S, Zhang W, Zheng B, et al. (2014) Heavy metal contaminant distribution features and the diffusion flux estimation in the sediments of Shahe reservoir, Beijing. J Saf Environ 14(2):244-249 . doi:10.13637/j.issn.1009-6094.2014.02.051 in Chinese

Zhang Q, Jiang G (2005) Polychlorinated dibenzo-p-dioxins/furans and polychlorinated biphenyls in sediments and aquatic organisms from the Taihu Lake, China. Chemosphere 61(3):314-322. doi:10.1016/j. chemosphere.2005.02.099

Zhang Y, Lu Y, Xu J, et al. (2011) Spatial distribution of polycyclic aromatic hydrocarbons from Lake Taihu, China. Bull Environ Contam Toxicol 87(1):80-85. doi:10.1007/s00128-011-0292-1

Zhang Y, Shi GL, Guo CS, et al. (2012) Seasonal variations of concentrations, profiles and possible sources of polycyclic aromatic hydrocarbons in sediments from Taihu Lake, China. J Soil Sediment 12(6):933-941. doi:10.1007/s11368-012-0526-9

Zhu G, Qin B, Gao G (2005) Direct evidence of phosphorus outbreak release from sediment to overlying water in a large shallow lake caused by strong wind wave disturbance. Chin Sci Bull 50(6): 577-582. doi:10.1007/BF02897483 